\title{
Modeling Entrepreneurial Innovation: A Study on Economic Development
}

Ebrahim Bonyadi ( $\square$ ebrahim.bonyadi@ut.ac.ir )

University of Tehran https://orcid.org/0000-0002-3919-0871

\section{Lida Sarreshtehdari}

University of Tehran

\section{Research}

Keywords: Business Activities, Innovation in Business, Economic Development, Economic Resilience, Chinese Restaurant Process, Blackwell-MacQueen urn scheme

Posted Date: March 23rd, 2020

DOI: https://doi.org/10.21203/rs.3.rs-18217/v1

License: (1) This work is licensed under a Creative Commons Attribution 4.0 International License. Read Full License 


\title{
Modeling Entrepreneurial Innovation: A Study on Economic Development
}

\author{
Ebrahim Bonyadi ${ }^{\mathrm{a}, *}$, Lida Sarreshtehdari ${ }^{\mathrm{b}}$ \\ ${ }^{a}$ School of Mathematics, Statistics, and Computer Science, University of Tehran, Iran \\ ${ }^{b}$ Faculty of Entrepreneurship, Global Entrepreneurship Monitor Office, University of Tehran, Iran
}

\section{Corresponding author:}

Corresponding author: Ebrahim Bonyadi*

Mailing address: Iran, Tehran, Amir abad, Farshi Moghaddam Street, University of Tehran, Faculty of Entrepreneurship, Global Entrepreneurship Monnitr (GEM) Office.

Mobile: +989196740546

E-mail: ebrahim.bonyadi@ut.ac.ir

\section{Ebrahim Bonyadi}

Master of Science, Mathematical statistics

Faculty of Mathematics, Statistics, and Computer Science, University of Tehran, Iran

ebrahim.bonyadi@ut.ac.ir or ebrahim.bonyadi@yahoo.com

phone number: +989196740546

\section{Lida Sarreshtehdari}

Master of Science, Entrepreneurship

Faculty of Entrepreneurship, Global Entrepreneurship Monitor Office, University of Tehran, Iran

$\underline{\text { lsarreshtedari@ut.ac.ir }}$

Phone number: +989109753432

\section{Competing interests}


There is no competing interest.

\title{
Authors contributions
}

Ebrahim Bonyadi: Conceptualization, Methodology, Software (including R programing language, and SPSS), Validation, Formal analysis, Data Curation, Writing - Original Draft, Writing - Review \& Editing, Supervision, Project administration.

Lida Sarreshtehdari: Investigation, Resources, Formal analysis, Writing - Original Draft, Visualization, Project administration.

\begin{abstract}
Modeling complex concepts, especially in the field of management science, will help researchers to get a better understanding of the relationship between insensible and multidimensional phenomena. The relationship between entrepreneurship and economic development has been repeatedly discussed by researchers. With reference to various research, the impact of innovative entrepreneurial activities on the growth and development of economies is clear to all.

This study attempts to provide a mathematical model in support of the accuracy of this relationship. Stochastic processes and probabilistic models have widely been used to perform this modeling. The underlying result of this model is a function by which the exact parameter of entrepreneurial performance can be calculated and also, by applying this model, the relationship between the innovation index and entrepreneurship is justifiable. Also, based on this modeling, the level of entrepreneurship of countries can be ranked based on innovation.
\end{abstract}

Keywords: Business Activities, Innovation in Business, Economic Development, Economic Resilience, Chinese Restaurant Process, Blackwell-MacQueen urn scheme.

\section{Introduction}


Discovering models comprising the business sector (economic-based activities) and the economic status, simultaneously, will help scholars and policymakers to provide full informative and accurate plans of getting developed. As Schumpeter (1934) has acknowledged, the innovationdriven entrepreneurial activities are one of the most influential parts of the business sector that undoubtedly move the economics status forward.

In responses to points raised by present-day societies, in the context of economic development, economists have used theories and empirical research to explain the cause of economic development.

To begin with, presenting a simple definition of economic development is required which is fulfilled by Coccia (2019). According to Coccia (2019), economic development is a multidimensional process whereby the economic health and quality of life will emerge also.

Moreover, economic growth refers to long-term development which derived from the industrial, agriculture, self-employment activities of the society under study.

Further, according to comprehensive documents gathered by Coccia (2010, 2014, 2014b, 2018a), the key factors of development in societies are the fostering the life health, the growth of wealth, new knowledge and technology generation, and so on. The suitable social systems with high justice, democracy, an effective education system, flexible culture, appropriate economic programs, convenient programs of policymakers, and more valuable innovative outputs will be able to foster the economic development.

As a result, as Fagerberg (2003) stated, economic development is a final outcome of the business sector that will result in economic growth and, from the view of scholars, is an appropriate key to identify the factors affecting the business viability.

So far, many researchers (like Edward, 2018; Faghih, Bonyadi, and Sarreshtehdari, 2019; Yeager, 2018; Nafziger, 2005) have published many findings in line with evaluating the factors influencing this intricate phenomenon (economic development) from various standpoints. As a summary of all researches until now, foremost, entrepreneurship plays a key role in economic development. Furthermore, nowadays, entrepreneurship, as an economic mechanism, has been widely recognized as a fundamental factor affecting economic development worldwide (Baum et al., 2007).

Although, due to nonadherence to primary rules of launching and managing a business, entrepreneurship may have a negative effect on economic development, especially in 
underdeveloped economies, according to Tomma, Grigorea, and Marinescu (2014), economic development and entrepreneurship are in a positive and strong relationship.

Likewise, innovation and entrepreneurship are recognized as the key to competitive and dynamic economies. That means countries and regions with brilliant innovation and entrepreneurship ecosystems lean toward a higher productivity rate, leading to increased economic growth and more robust job creation (World Bank, 2015).

Additionally, the classical and neoclassical economics schools analyze developmental economics in terms of allocating scarce resources to support optimal growth, production, and generation of goods and services, whereas the new economic approaches clarify economic development with social, political, economic and organizational factors, in order to improve living standards and reduce poverty, eliminate inequality in income between people and improve the quality of life (Todaro and Smith, 2003; Coccia, 2017; Gerschenkron, 1962).

\section{Literature and Review}

\subsection{Economic Development and Innovation}

The innovation lies at the heart of the modern economy (Lounsbury, et al., 2019). Innovation is considered an underlying cause of economic development and an important source of competitive advantage and also as a source of long term economic growth (Ray, 1980.; Martins et al., 2015; Fuentelsaz et al., 2018).

Does innovation affect economic development? If the answer is positive, how is the procedure of innovation impact on economic development? This is our main question in this research, which we will provide statistics-based arguments to respond to these questions.

In the first place, let us acknowledge that Innovation provides a circumstance that leads to the advent of new products and services. As such, the process of new products and services may cause the creation of the new organization or enhancement and development of existing organizations' activities (Schumpeter, 1939). Innovation is treated as the "golden ingredient" of entrepreneurship in the quest for increased competitiveness and represents the main function of the highest-level entrepreneurs (Crudu, 2019). Research carried out by scientists (e.g. Griffith, et al., 2006) has indicated that innovation, in general, is an action that is taken to improve and enhance the 
technology, new services, and products. Also, the influence of innovation on economic growth is largely addressed in economic literature (Crudu, 2019).

Another hand, innovation often being considered as a dynamic technology embedded in a social and economic process that comprising the interaction of people with a varied point of view and also comes from completely different motivations (Lionnet, 2003).

It is worth noting that innovation, especially in the business sector, will guarantee the new products, novel services, low-competitive jobs, and finally economic prosperity. There are wideranging interpretations of innovation that can be defined according to the individual's attitude in different fields like the economy and business science herein (Granstrand, 2004). Research carried out by scientists (e.g. Griffith, et al., 2006) has indicated that innovation, in general, is an action that is taken to improve and enhance the technology, new services, and products. This vast approach of innovation makes it possible for other researchers to consider any kind of updating or producing new goods or services as an innovative action (Kline and Rosenberg, 1986; Bell and Pavitt, 1993; Cooke, Eriksson, 2011).

For instance, the production of a new commodity by offering a different service can be considered as an innovation in the business sector; or offering a new product that creates a job opportunity may be treated as an innovation in the service sector.

As an additional explanation, innovation in addition to producing new technology can directly produce products and services that are very unique. In other words, such less-competitive products refer to their innovatively (Capello, Caraglui, and Fratesi, 2015).

Since innovation leads to the production of new technology, products, and services, this will also create new requirements and demands by the public. Looking for the fulfillment of new needs and more demands made by people, different jobs and businesses also will appear automatically. Therefore, innovation not only improves the quality of life, but also intensify people's economic potential through the production of new occupations and, in summary, according to research conducted by Schumpeter (1934), innovation will increase entrepreneurial activities leading to economic development.

More importantly, innovation is essential for sustainable growth of economic development in modern economies and as well as innovation is crucial for value creation and employment generation (Gerguri, Ramadani, 2010). 
As Bristow and Healy (2018) have acknowledged, innovation can be considered as the main driver of economic change and major disrupter of production functions as well as it is the source of longterm economic transformation.

According to Acha and Tunzelmann (2004), the status of technology (low-tech and high-tech) in industries is one of the most determinant factors which indicates the level of the economies' innovation (in terms of economic development). On the other hand, innovation not only accurately assesses the technology of the process of the production of products and services but also focuses on the type of distribution of new products and technology in different areas.

It is worth noting that the importance of innovation is so that, even in so-called low-tech industries, there may be a lot of innovation going on, and the economic effects may be very large (Acha and Tunzelmann, 2004; Grossman and Helpman, 1991). In fact, taking the innovation into account as the main distinction between undeveloped and developed countries will be to researchers' advantage in making a logical decision.

Further, according to Ignatova (2019), innovation is essential for sustainable growth of economic development in economies. With these broad definitions, clearly, innovation positively affects economic development and finally will, in turn, lead to life health and social welfare (Hobday, 1995; Fagerberg, et al., 2004).

\subsection{Innovation and Economic Resilience}

Economic vulnerability is defined as the exposure of an economy to exogenous shocks, arising out of economic openness, while economic resilience is defined as the policy-induced ability of an economy to withstand or recover from the effects of such shocks (Aldrich and Meyer, 2014). Resilience economies employ a mix of regulations and norms (i.e., non-regulated but expected behavior) to shift standard business processes away from a focus on efficiency towards a focus on flexibility. It is noted that, nowadays, resilience has emerged as a concept to explain how economic systems adapt successfully to negative and shocks events.

If the economic system of a society resembles a machine with an input and one output section, then as much as innovation, technology, and manpower may affect the growth of the business and the economic development of the society, it can be said that preventing businesses from exit, 
increasing businesses viability and increasing economic resilience can equally lead to economic development, too (Bahadur and Doczi, 2016).

Today, one of the issues that policymakers and researchers have been involved in is: "how to increase the economic resilience of societies against the factors destructing economic (such as economic shocks, economic downturn, and so on)".

Business holders and policymakers have declared the essential importance of innovation on economic resilience against economic shocks. Meanwhile, they asserted that innovation has an effect on facilitating rapid recovery from economic shocks, namely, by which getting the previous equilibrium status will be more possible. (Bristow and Healy, 2018).

As debated in Territorial Observation in Europe (2014), there is a strong positive relationship between innovation and resilience outcomes. Meanwhile, regions with higher levels of innovative activities have the tendency to be able to resist against economic shocks more than those where innovation capabilities are lower (Territorial Observation No. 12, 2014).

Innovation is a driver of income growth which benefits everybody in society and, furthermore, innovation can help firms to withstand the economic crisis. Also, innovation may create diversity in businesses. It is worth mentioning that business diversification makes active competition in innovations and new products. This subject helps the economies to get succeed in the long term and contributes to meet more economic resilience (Stephanie, Raetze, and Scheuch, 2019).

With these explanations, when encountering exogenous and endogenous shocks, an economy is more resistant if there is a wide variety of businesses and occupations in the country. More importantly, since some businesses will go fail when economic crises occur, so by extending the diversification of business types, only a small portion of businesses would fail or go bankrupt (Faggian, 2018). As a matter of fact, by increasing the varieties of business types, the economic resiliency may go reinforced.

Generally, with increasing the job options in the labor market, in terms of innovative activities, competition among entrepreneurs will decrease and accordingly the risk of venturing into a business will be negligible. On the other hand, by increasing the opportunity of landing good jobs, life health and high wealth will emerge (Faggian, 2018).

Lastly and more importantly, in the cases that the exogenous shocks and threats are pressuring the country's economic system, diversification of careers and existence of numerous job options in the 
labor market will help the economic system to prevent the occurrence of the economic downturn (Davies, 2011).

This means that, for example, if environmental factors negatively influence only a specific type of jobs (for example the agriculture sector), then with the existence of the activities of other business sectors in society, the lack of activities of the agriculture sector can somewhat be compensable. In other words, in an innovation-economy, exogenous factors take negative effects only on a limited portion of businesses and other parts will keep going, whereas in a factor-driven economy, because of the lack of diversification in businesses, a great part of the business sector will be disrupted by inner/outer crises laid in the country.

In other words, an adequate number of distinct (variety) entrepreneurial activities in a country will increase the probability of resistant in the business sector when facing economic shocks (Diodato and Weterings, 2014). Thus, with the increase of the number of businesses (which is rooted in innovation), the business market will appear more resilient and, as a result, the society will not be under pressure of the economic recession and it will show more resilience and will be more durable when meeting the shocks.

In order to investigate the relationship between Innovation Index and Economic Resistance Index, we examined eleven ${ }^{1}$ linear and nonlinear regression-based models in table 1 . In these regression equations, we consider the Global Innovation Index (GII) as the effective variable (independent variable) and the Economic Resistance Index as the dependent variable.

${ }^{1}$ Linear, Logarithmic, Inverse, Quadratic, Cubic, Compound, Power, S, Growth, Exponential, Logistic. 
Table 1: The estimate of linear and nonlinear models for the relationship of Economic Resilience Index (as dependent variable) and Global Innovation Index (as the independent variable) ; Source: Authors' own table

\begin{tabular}{|c|c|c|c|c|c|c|c|c|c|}
\hline \multirow[b]{2}{*}{ Equation } & \multicolumn{5}{|c|}{ Model Summary } & \multicolumn{4}{|c|}{ Parameter Estimates } \\
\hline & R Square & $\mathrm{F}$ & df1 & $\mathrm{df} 2$ & Sig. & Constant & b1 & b2 & b3 \\
\hline Linear & .850 & 633.731 & 1 & 112 & .000 & -25.116 & 1.929 & & \\
\hline Logarithmic & .819 & 507.437 & 1 & 112 & .000 & -214.176 & 73.057 & & \\
\hline Inverse & .739 & 316.689 & 1 & 112 & .000 & 118.437 & -2436.428 & & \\
\hline Quadratic & .843 & 314.357 & 2 & 111 & .000 & -21.944 & 1.762 & .002 & \\
\hline Cubic & .849 & 227.036 & 3 & 110 & .000 & 62.081 & -5.057 & .176 & -.001 \\
\hline Compound & .770 & 375.401 & 1 & 112 & .000 & 8.977 & 1.041 & & \\
\hline Power & .787 & 412.742 & 1 & 112 & .000 & .143 & 1.582 & & \\
\hline $\mathrm{S}$ & .754 & 342.890 & 1 & 112 & .000 & 5.305 & -54.382 & & \\
\hline Growth & .770 & 375.401 & 1 & 112 & .000 & 2.195 & .041 & & \\
\hline Exponential & .770 & 375.401 & 1 & 112 & .000 & 8.977 & .041 & & \\
\hline Logistic & .770 & 375.401 & 1 & 112 & .000 & .111 & .960 & & \\
\hline
\end{tabular}

The estimation of regression models between these two variables was performed using data in 2017. The criterion of assessing and identifying the best model fitted on variables is the "coefficient of determination" which is known as R-Square. The higher the coefficient of determination in a model guarantees the sufficiency of the model in predicting the fluctuations of the dependent variable by using the independent variable(s).

Considering the proposed models, from among 11 models, although all models are significant at the level of $95 \%$ (the p-value or sig. is less than 5\%), because the coefficient of determination in the linear model is more than other models, so this is the best predictor model for describing the relationship between the Global Innovation Index and Economic Resistance Index. On the other hand, the calculations performed in this model show an R-square amount of 85 percent for the linear model. This means that the Global Innovation Index is capable of predicting almost 85 percent of changes in the index of Economic Resilience worldwide which, in terms of statistics, is too remarkable amount.

The estimated linear model is as follows:

$$
y=-25.12+1.93 * x
$$


In which, $y$ denotes the Economic Resilience Index and $x$ is a notation for the Global Innovation Index and, furthermore, both $x$ and $y$ fall into the range of $(0,100)$.

Although the amount of Economic Resilience Index shall never fall into the negative domain, according to the calculated equation, when $\mathrm{x}$ sets equal to zero, it is easy to know that $\mathrm{y}$ (Economic Resilience Index) is about -25 . The interpretation of this contradiction is that if a country is not capable of presenting the innovative programs, it can be said that its economic system is at risk. To refrain from the negative range for the dependent variable, the range of $(10,100)$ is recommended for the independent variable herein.

To get more understanding of the relationship between the said indexes, Figure 1 has presented the scatter plot and the estimated line.

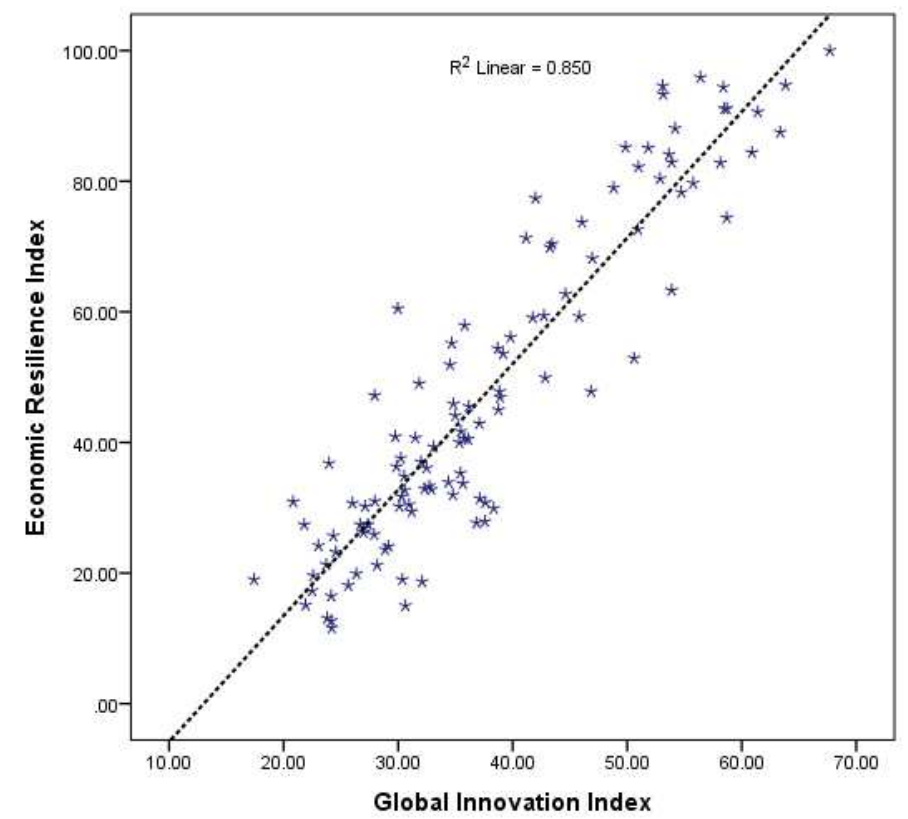

Figure 1: Relationship between Economic Resilience Index and the Global Innovation Index; Source: Authors' own figure

Figure 1 displays a strong and direct connection between the Economic Resilience Index and the Global Innovation Index. According to Figure 1, as much as countries are innovative (for example in terms of technology, new products, and new services) the Economic Resilience Index will also increase therein. Thereby, because of the public's new demands and needs, the new products will generate new businesses as well. 
Therefore, the innovation, which has led to a growth in the number of businesses at the community level, directly increases economic flexibility and accordingly, in other words, will reinforce the economic resistance in society. Thus, creating an appropriate background at the country level for identifying the best opportunities for entrepreneurship can help policymakers to decline the stresses resulted from economic shocks/crises. It is worth noting that our aim in this study is to provide a statistical and mathematical-based model to describe theoretically and logically the relationship between innovation-driven entrepreneurship and the total entrepreneurship index.

\section{Chinese Restaurant Process and Concept of Innovation}

Prior to introducing a coherent and logical model explaining the relationship between innovation and entrepreneurship, we firstly will describe the Chinese Restaurant Process (CRP). Statistics is a science that has intense dependence on data. In order to identify the characteristics and properties of a population, it is necessary to estimate some of the unknown parameters of the population under study by the data available. Since all the units of the population are not available, it is absolutely essential to select an appropriate and completely randomized sample of the community to continue the assessment.

Meanwhile, the larger sample size chosen from the population will result in a more accurate estimate of the unknown parameters. Likewise, the lack of repetitive data in the sample will give the researcher further information about the units of the big population. While the existence of repetitive data not only will not lead to a reduction of the error of estimation but will make a biased estimate of the parameter in question.

On the whole, one of the goals that statisticians are always following is the use of big sample size and non-repetitive information. There are several methods for identifying non-repetitive data in a sample. The Blackwell MacQueen urn scheme and the Chinese Restaurant Process are two different methods that can predict the number of distinct data (different clusters) in a sample (Antoniak, 1974). The basic assumption of these approaches is to use clustering information relationships in such a way that the same (repetitive) data are in the same clusters.

For example, if there is a 100-unit sample, and if 20 units of this sample are repetitive, it is easy to know that these 20 units are equal to some of the 80 non-repetitive unites. In fact, there is only a sample of 80 non-repetitive units. Now by defining 80 distinct clusters, in which there is at least 
one unit in any 80 clusters, one can distribute the repetitive 20 sample units into their same clusters. To get more feeling for Blackwell MacQueen Process and the Chinese Restaurant study the following text.

\subsection{Blackwell-MacQueen Urn Scheme}

In order to generalize the Polya $\mathrm{Urn}^{2}$ Model, as a possibility for prediction of a complex phenomenon, Blackwell and MacQueen introduced a scheme entitled "Blackwell-MacQueen Urn scheme" (Blackwell and MacQueen, 1973).

This scheme is a linear mixture of the Polya Urn model and a prior distribution (Müller and Quintana, 2004) which is an extension of the Dirichlet process also. Prior to depict how BlackwellMacQueen urn scheme and Chinese Restaurant Process work, let us define some terms.

Indeed, the objective that we pursue in this study is based on the implementation of some statistical concepts onto their equivalent concepts in the field of business and economic science.

In doing so, when we talk about "data", its equivalent concept in business can be referred to as "business or job position". When we talk about "Probability Density Function" or "Cumulative Distribution Function" in statistics, you can consider them as the "business environment properties". When we talk about the "prior density function", it can be considered as the "previous career experience" or "former information about the business". Finally, when we tell something about the "repetitive data", it can be interpreted as the " same businesses or jobs " which activate in the labor market, not the rare, low-competitive, or innovative businesses. To sum it all up, see table 2 .

Table 2: The equivalent phrases, in statistics and the business sector, applied throughout this study; Source: Authors' own table

\begin{tabular}{|r|l|l|}
\cline { 2 - 3 } \multicolumn{1}{l|}{} & The phrase in statistics & The equivalent phrase in business \\
\hline $\mathbf{1}$ & Data & Business positions \\
\hline $\mathbf{2}$ & Repetitive data & Same businesses and jobs \\
\hline
\end{tabular}

\footnotetext{
${ }^{2}$ A collection of simple and probability-based models, which is developed by considering colorful balls and several urns, that are widely used in other sciences such as economics, biology, medicine, engineering, etc.
} 


\begin{tabular}{|c|l|l|}
\hline $\mathbf{3}$ & Non-repetitive simulated data & Innovative businesses \\
\hline $\mathbf{4}$ & Probability Density Function & Business environment properties \\
\hline $\mathbf{5}$ & Cumulative Distribution Function & Business environment properties \\
\hline $\mathbf{6}$ & Prior density function & $\begin{array}{l}\text { Previous career experience or former } \\
\text { information about businesses }\end{array}$ \\
\hline
\end{tabular}

To get more feeling for the real nature of interpretations and concepts defined above, consider the following stratification:

Suppose one individual is going to venture into a business. Clearly, there are two choices for this new entrepreneur:

- First, he/she will launch a new innovative business that is unique or, at least, is rare in his/her living region.

- Second, according to his/her attitude, knowledge, or capability, he/she will launch a repetitive business that existing before in the area of living.

The question that comes up here is: How can predict the probability of choosing a new or repetitive business in one society?

More precisely, if we suppose a function named "decision function" that applies to predict the probability of business selection, therefore, in line with modeling this decision function, what function will accurately predict which type of businesses, whether new or repetitive, will be chosen by a new entrepreneur.

Clearly, using a mixture function, which is made by different relevant components and unique weights, is the method for reaching the answer.

In such a case, for simulating the data of a considered function (decision function), the method that statisticians offer to researchers is the nonparametric method which is based on the Dirichlet process model (Ferguson 1973). For the purpose of forming this model, two portions required to be studied individually.

- First, the status of repetitive businesses that are running in the current business market. 
- Second, the area of new businesses that are innovative and have not been occupied in the business market as yet.

Once again, it is worth mentioning that to implement the methods of statistics on the business market, hereinafter, throughout the remainder of this study, either of "business" or "data" and additionally the "innovative businesses" or "non-repetitive simulated sample" will be used equivalently.

Have noticed that the choice of data from either of portions, the existing sample of data or newly generated data sample, depends on the weights that allow the researcher to choose a sample (repetitive or new) in any step of the simulation. To get more feeling of the simulation of data, keep reading with the remainder of this subsection.

According to the Blackwell-MacQueen urn scheme, the new data (herein new businesses) come from a density function which is proportional to $A=\frac{\alpha}{n+\alpha}$ and the repetitive data (repetitive businesses herein) come from the set of previous data (existing businesses) which is proportional to $B=\frac{n}{n+\alpha}$. In which $n$ is the number of businesses (the size of the sample).

Note that according to the concept of some of the statistical models (like Dirichlet Process), the notation of $\alpha$ is a positive parameter that is called "concentration parameter", "dispersion parameter", or "precision parameter". In the next steps, the applicability of this unknown parameter will be thoroughly discussed.

The first fraction (A) calculates the coefficient that includes all endogenous and exogenous factors affecting the business launching. Additionally, this coefficient is unique for any country/economy. For example, it can be numerically showed that the Cumulative Distribution Function of job creation in the United States of America varies from this function in France. Furthermore, coefficient A shows that an innovative and low-competitive business in a country will generate proportional to A (i.e. A is the rate of individuals in a country who lean toward an innovative business).

So if $\alpha \rightarrow \infty$ then $A \rightarrow 1$. This means the new innovative business will be launched with the probability $1(100 \%)$, if $\rightarrow \infty$. As such, the great amount of alpha will result in a higher probability of emerging new innovative businesses.

On the other hand, the second fraction (B) means the coefficient of choice of repetitive businesses in a country. This means, with probability B, an individual would venture into a repetitive business. Note that if $\alpha \rightarrow \infty$ then $B \rightarrow 0$. This means, when the precision parameter increases, the 
probability of launching a repetitive business is about zero. Additionally, A and B are complementary, namely $\mathrm{A}+\mathrm{B}=1$.

In summary, according to Blackwell MacQueen mixture model, the new business launched by a new entrepreneur is:

1. an innovative business with probability A or;

2. a repetitive business with probability $B$.

It is worth mentioning that $\alpha$ plays the principal role in forming the decision function model.

With these explanations, what seems to be more important in this study is the precision parameter which is able to determine the amount of business innovation across countries. To get more understanding about the importance of the role of the precision parameter, see the following example.

Example- Suppose $\xi$ denotes the space of colors, and $X_{i}$ is a variable that represents the color of the $i t h$ ball which has extracted from the urn. First, we take out a color from the space of colors, $\xi$, with the probability of $G_{0}$ (this is the prior density function that gives a non-repetitive data), this means $X_{1} \sim G_{0}$. In the second step, we can select a non-repetitive data from the prior density function proportional to $\frac{\alpha}{n+\alpha}$, or a repetitive unit with proportional to $\frac{n}{n+\alpha}$. This algorithm can be applied until the $n t h$ sample unit to be generated.

In general, the predictor function in the Blackwell-MacQueen scheme is as follows:

$$
P\left(X_{n+1} \in A \mid X_{1}, X_{2}, \ldots, X_{n}, G_{0}\right)=\frac{\alpha}{n+\alpha} G_{0}(S)+\frac{1}{n+\alpha} \sum_{i=1}^{n} \delta_{X_{i}}(S)
$$

In which $S$ subset of $\xi$, and $\delta_{X_{i}}(S)$ is an indicator function that is defined as follows:

$$
\delta_{X_{i}}(S)=\left\{\begin{array}{ccc}
1 & ; & \text { if } X_{i} \in S \\
0 & ; & \text { otherwise }
\end{array}\right.
$$


$X_{n+1}$ is the notation of the kind of business (whether innovative or repetitive) that the $(n+1) t h$ entrepreneur will launch it. Namely, if the business of $(n+1)$ th individual is repetitive then $\delta_{X_{i}}(S)=1$ and if his/her business is unique, then a new sample will be generated from the prior density function ${ }^{3} G_{0}(S)$.

Equations (2) and (3) show that if $n \rightarrow \infty$ then the new observation of the sample (new business), $X_{n+1}$ th unit has the tendency to be a repetitive unit.

For example, in terms of business and entrepreneurship, supposes an individual want to launch a business, now, if in his/her living area there is a type of business that most of the people are venturing into, therefore, this new entrepreneur will prefer to launch the same business proportional to $\frac{1}{n+\alpha} \sum_{i=1}^{n} \delta_{X_{i}}$. That means, as much as the number of distinct businesses in a country increases, the probability of launching a new non-repetitive business is low.

With respect to the predictor function (equation 2), if $\alpha \rightarrow \infty$ then the new observation (new business) will be generated from the prior density function ${ }^{4} G_{0}(S)$. Regards to the previous example, if the precision parameter increases then the new entrepreneur prefers to initiate a new entrepreneurial activity that is completely innovative and less-competitive.

Notice that finding the same concepts of some statistical terms such as precision parameter, prior density function, sample simulation and so forth, in other sciences, needs a parallel implementation For example, in the science of business and entrepreneurship, the precision parameter of the Blackwell-MacQueen urn scheme can be deemed as the amount of skill, knowhow, risk acceptance and so on. By the way, it seems the precision parameter in the business sectors refers to the total awareness of people toward business success.

As a result, equation (2) reveals that as much as the precision parameter increases, the number of non-repetitive businesses will increase, too. In other words, the expansion of new and innovative businesses will be caused by the growth of the precision parameter.

To move forward in line with creating the decision function, let us set all the same businesses into a cluster (category). Clearly, the number of distinct clusters demonstrates the number of distinct

\footnotetext{
${ }^{3}$ Suppose $G_{0}(S)$ is a probability function that, in parametric or nonparametric manner, can present the characteristics of new business status of country. Furthermore, clearly, this function may be different in any country.

${ }^{4}$ Herein, the Prior Density Function can be considered as the set of businesses that have not yet been launched in the area of interest.
} 
businesses. With these explanations, it can be said the number of different clusters reflects the exact number of innovative businesses. By having these definitions, in the next subsection, the relationship between the precision parameter and the number of innovative businesses will be illustrated.

By applying equations (2) and (3) with the use of R programing language, a set of data has been simulated. Figure 2 depicts the procedure of changes in the number of clusters (non-repetitive businesses) with respect to the precision parameter.
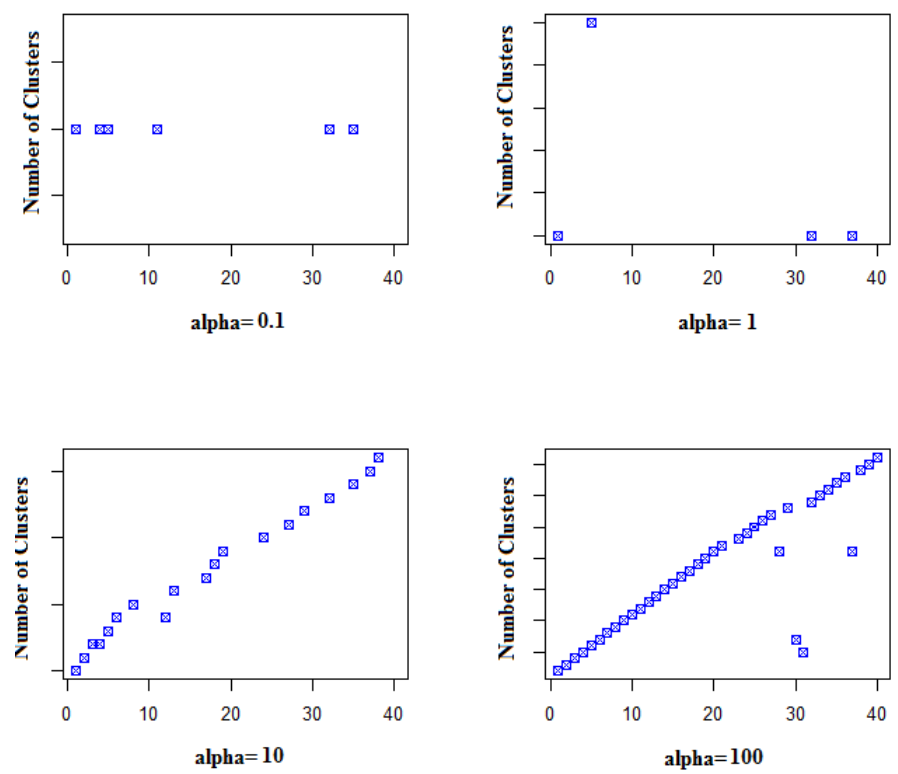

Figure 2: The growth of the number of clusters (innovative businesses herein) when the precision parameter increases; Source: Authors' own figure

Figure 2 has brought 40 units simulated from the $\operatorname{Beta}(\alpha=2 ; \beta=3)$ distribution with the use of the Blackwell-MacQueen urn scheme. Suppose the vertical axis is related to the number of clusters (number of the non-repetitive businesses) and assume that the horizontal axis shows the position of the units. As is shown, when $\alpha=0.1$ there is only one cluster. This means all 40 businesses are repetitive and are of one kind (note that in this circumstance, if an economic shock menaces the economic system of a country, then the economic downturn of the country is unavoidable).

When $\alpha=1$ then the number of clusters is 2 , when the precision parameter is equal to 10 then the number of clusters is about 17 , and finally when the precision parameter is 100 the number of non- 
repetitive clusters is about 40 . This simulation proves that by increasing the precision parameter, any simulated unit (or any new entrepreneurship) is different than other units and almost it can be said that when $\alpha \rightarrow \infty$ any entrepreneurial activity is unique and full-innovative.

Therefore, in order to have a careful investigation of the innovation-driven businesses, the precision parameter seems to be applicable.

Forasmuch as, the Innovation Index is able to describe the status of the economic development in a country (according to Figure 1), and additionally since the innovative entrepreneurial activities are the main distinction between developed and non-developed economics (Schumpeter, 1934) therefore, modeling the process of economic development with the use of Dirichlet process, Blackwell-MacQueen urn scheme, and Chinese Restaurant Process not only will work appropriately but will show the vast applicability of some said statistical simple theories.

Blackwell-MacQueen urn scheme showed that the precision parameter will affect the innovation of the concept under study (herein entrepreneurship), which is the topic that many scholars follow it to investigate into the economic status across different countries. In the next subsection, we will try to model the economic development with the use of a stochastic process dependent on the Entrepreneurship Index and the Entrepreneurial Innovation Index.

\section{Chinese Restaurant Process (CRP)}

Reduced to the simplest possible description, the Chinese Restaurant Process (CRP) shows us a distribution over clusters. Suppose that we have a collection of observations (different types of businesses), and with respect to their similarity, we want to cluster them into several groups. This can be done by the Chinese Restaurant Process (CRP).

The Chinese Restaurant Process gets its name from a metaphor on the basis of Chinese restaurants located in San Francisco that have the capacity of a limitless chair. In this metaphor, every possible group corresponds to a "table" in an infinitely large Chinese restaurant (in terms of entrepreneurship, the term "table" refers to a specific type of business that some entrepreneurs have launched). Each observation corresponds to a "customer" entering the restaurant and sitting at a table ("customer" in the Chinese restaurant process will replace with the "entrepreneur" in the 
business market). Additionally, the customers are assumed to prefer sitting at popular tables ${ }^{5}$ (this often occurs in factor-driven or low-income economies), but nevertheless, there is always a nonzero probability that a new customer will sit at a currently unoccupied table (this often occurs in innovation-driven or high-income countries).

To see how this works, suppose that there are currently $N$ customers (entrepreneurs, in terms of entrepreneurship) sitting in the restaurant, and let $z_{i}$ be an indicator variable that specifies to us in which table the $i$ th customer will sit. Hence, there is a vector of "table assignments", $\mathrm{z}=\left(z_{1}, z_{2}\right.$, . $\left.\ldots, z_{N}\right)$. For example, if the vector of table assignments for $\mathrm{N}=6$ customers were given by $\mathrm{z}=(3$, $3,2,3,1,4$ ), then there would be three customers sitting at table 3 (i.e., customers number 1,2 and 4), and one customer at table 2 (i.e., customer 3), one customer at table 1 (i.e., customer 5) and one customer at table 4 (i.e., customer 6 ). The probability of this combination among 6 customers, with the use of predictor function that was provided by the Blackwell-MacQueen (equations (2) and (3)) urn scheme, is as follows:

$$
\begin{gathered}
P\left(Z_{1}=3 ; Z_{2}=3 ; Z_{3}=2 ; Z_{4}=3 ; Z_{5}=1 ; Z_{6}=4\right)= \\
P\left(Z_{1}=3\right) \times P\left(Z_{2}=3 \mid Z_{1}=3\right) \\
\times P\left(Z_{3}=2 \mid Z_{1}=3 ; Z_{2}=1\right) \times P\left(Z_{4}=3 \mid Z_{1}=3 ; Z_{2}=3 ; Z_{3}=2\right) \\
\times P\left(Z_{5}=1 \mid Z_{1}=3 ; Z_{2}=3 ; Z_{3}=2 ; Z_{4}=3\right) \times P\left(Z_{6}=4 \mid Z_{1}=3 ; Z_{2}=3 ; Z_{3}=2 ; Z_{4}=3 ; Z_{5}=1\right)= \\
\frac{\alpha}{\alpha} \times \frac{1}{1+\alpha} \times \frac{\alpha}{2+\alpha} \times \frac{2}{3+\alpha} \times \frac{\alpha}{4+\alpha} \times \frac{\alpha}{5+\alpha}
\end{gathered}
$$

The actual table numbers do not mean anything: they are just appropriate indicator variables. That means, $z=(1,1,2,1,3,4)$ and $z=(2,2,1,2,4,3)$ are effectively equivalent. Next, let $n_{k}$ denote the number of people sitting at the $k t h$ table (number of the entrepreneurs that have launched the same business known as $k$ ), and let $K$ denote the total number of non-empty tables. Then the "counts" vector $n=\left(n_{1}, \ldots, n_{K}\right)$ shows us how many people are at each table/business (this vector displays the number of clusters with the number of units into each cluster). To stick with our

\footnotetext{
${ }^{5}$ According to the Global Entrepreneurship Monitor (GEM) annual research, in the factor-driven economies, most of the entrepreneurs prefer to get into a similar business whereas, in the innovation-driven economies, each entrepreneur by perceiving the business opportunities desires to venture into an innovative and low-competitive business.
} 
running example, if the table assignment vector is $z=(3,3,2,3,1,4)$, then the count vector would be $n=(1,1,3,1)$.

Note that $\sum_{k=1}^{K} n_{k}=N$. Now after these explanations, it is very simple to apply the Chinese Restaurant Process. If there are $N$ customers sitting in a restaurant, then the probability that customer $N+1$ sits at the $k t h$ table (or the probability that entrepreneur $N+1$ launch the kth business) is proportional to the popularity of that table. As follows (according to equation (2)):

$$
P\left(Z_{N+1}=k \mid n, \alpha\right)=\frac{n_{k}}{N+\alpha}
$$

Because in the Chinese Restaurant Process, the choice of each table by a customer is an arbitrarily and random issue, so this will randomize the number of clusters in the process. Thereby, there is no difference in customer relocation, and this will play a key role in the simulation algorithm to generate new data as well as in determining the number of clusters.

More precisely, in terms of entrepreneurship, it does not matter which entrepreneur would launch any business. what seems to be important is the number of innovative businesses (clusters) that will influence economic development and accordingly the life health.

If $\vartheta_{i}$ for $i=1,2, \ldots, n$ be considered as an indicator function related to the ith customer. Namely, $\vartheta_{i}=1$ if $i$ th customer chooses a new table (or equivalently $\vartheta_{i}=1$ if the $i$ th entrepreneur launches a new innovative business) and $\vartheta_{i}=0$ otherwise. In addition, let us define $K$ as the variable that counts the number of tables chosen by $n$ costumers (or equivalently, $K$ is considered as a variable that counts the number of distinct businesses that have been handled by $n$ entrepreneurs). With these explanations, the expectation value (mean value) and variance of clusters (distinct businesses) can be calculated by the following argument:

$$
E(K \mid n)=E\left(\sum_{i=1}^{n} \vartheta_{i} \mid n\right)=\sum_{i=1}^{n} P\left(\vartheta_{i}=1\right)=\sum_{i=1}^{n} \frac{\alpha}{\alpha+i-1}=\alpha(\psi(\alpha+n)-\psi(\alpha)) \approx \alpha \cdot \log \left(1+\frac{n}{\alpha}\right)
$$

And,

$$
\operatorname{Var}(K \mid n)=\alpha(\psi(\alpha+n)-\psi(\alpha))+\alpha^{2}\left(\psi(\alpha+n)^{\prime}-\psi(\alpha)^{\prime}\right) \approx \alpha \cdot\left(\log \left(1+\frac{n}{\alpha}\right)-1\right)
$$


In which, $\psi($.$) represents the digamma function. Clearly, when the precision parameter, \alpha$, increases then the average value of the number of clusters (distinct businesses) will increase also. Additionally, when the number of customers (or the number of entrepreneurs) increases, the average value of clusters will increase logarithmically.

This means that the growth of the precision parameter has a more effective impact on the number of clusters rather than the rise in the number of customers. Because the precision parameter has a direct and positive effect on the number of clusters whereas the number of total costumers (herein businesses) is in a logarithmic relationship with the number of clusters.

\section{Application of Method}

The plenty number of tables in a restaurant show the prosperous status thereto. Namely, when a restaurant owner makes a decision to increase the number of tables of his/her restaurant, this reflects the developing status of the restaurant. Equivalently, by considering the labor market of countries as a restaurant, obviously, when the number of innovative businesses in a country is extending, this proves the fact that the economy of the country is developing also (Schumpeter, 1934).

With regard to the equation of average for the number of clusters (equation (5)), in which:

$$
E(K \mid n) \approx \alpha \cdot \log \left(1+\frac{n}{\alpha}\right)
$$

In terms of entrepreneurship, $E(K \mid n)$ is the Entrepreneurial Innovation Index (or Rate of Entrepreneurial Innovation) which can be gained from the Global Entrepreneurship Monitor (GEM) annual reports.

In other words, the expectation value of the number of distinct clusters is the anticipated amount of the number of innovative businesses (equation (6)). Furthermore, $n$ can be considered as the Entrepreneurship Index (or Rate of Entrepreneurial Activities) that is achievable by the researches of the Global Entrepreneurship Development Institute annual reports, too. Note that the Entrepreneurship Index comprises innovative businesses and others. Namely, $n=\sum_{i=1}^{N} f_{i} k_{i}$. In 
which $k_{i}$ is a notation of the ith distinct business type and $f_{i}$ counts the number of businesses of ith type and $N$ demonstrates the total number of business.

In the view of statistics, to estimate the parameter $n$, the Binomial distribution is functional, in which the unbiasedness, as well as the minimum squared error, have been strictly applied. In such a case, the statistic (estimator function) which is able to estimate the unknown parameter $n$, with least error, is the Arithmetic Mean. According to mathematical statistics methods, the estimator of the number of total businesses, herein, can be written as follows:

$$
\hat{n}=N p
$$

Where $\hat{n}$ is a notation for the estimator of the number of businesses. Additionally, according to the definition of entrepreneurship by $\mathrm{GEM}^{6}$, the Entrepreneurship Index can be replaced the $\hat{n}$.

By having all considered arguments above, the equation of average of the number of clusters provided by Blackwell-MacQueen urn scheme and Chinese Restaurant Process, equation (2) can be rewritten as follows:

Entreprenurial Innovation Index $\approx \alpha \cdot \log \left(1+\frac{\text { Entrepreneurship Index }}{\alpha}\right)$

In which the Entrepreneurial Innovation Index and the Entrepreneurship Index are known. What is unknown in equation (8) is the precision parameter that we make an attempt to find its effect on this equation.

By replacing the calculated amounts of the Entrepreneurial Innovation Index and the Entrepreneurship Index with the relevant unknown parameters in equation (8), the precision parameter will be obtained. More importantly, by using this equation both the Entrepreneurial Innovation Index and Entrepreneurship Index are summarized in a new index entitle "precision parameter". The way that we pursue throughout the remainder of this study is finding a new

\footnotetext{
${ }^{6}$ The general definition of entrepreneurship by Global Entrepreneurship Monitor (GEM) is any business activity regardless of its ability to make money.
} 
concept indexing the relationship between precision parameter and economic development (that, according to Schumpeter's mention, is strongly related to innovative entrepreneurship).

Using equation (8), Figure 3 shows the trend of growth of the Entrepreneurial Innovation Index with respect to the precision parameter.

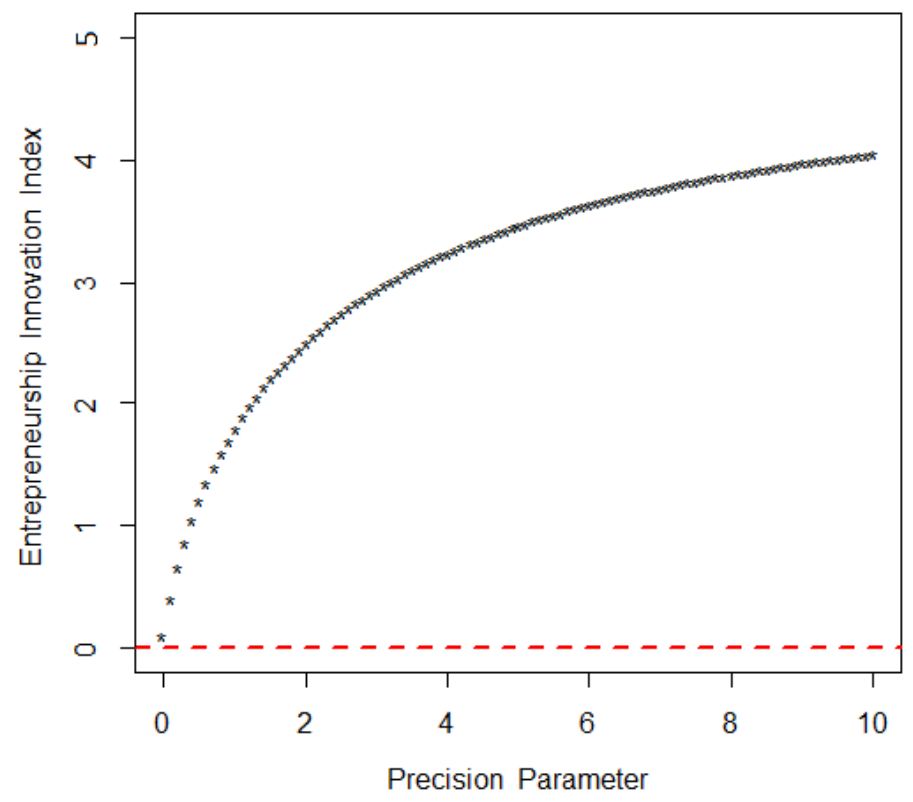

Figure 3: The relationship between the precision parameter and the Entrepreneurial Innovation Index; Source: Authors' own figure

This simulation of $\alpha$, at the level of $99 \%$, reaffirms the positive relationship between the precision parameter and the Entrepreneurial Innovation Index. Note that this chart is drawn only for a limited range of vertical and horizontal axes and may be extended.

If we set;

$$
f(\alpha) \approx \alpha \cdot \log \left(1+\frac{\text { Entrepreneurhsip Index }}{\alpha}\right)-\text { Entreprenurial Innovatin Index }
$$


Clearly, the root of function $f(\alpha)$ is exactly the amount of precision parameter, $\alpha$, that demonstrates the status of the economic development of a country derived from its entrepreneurial activities.

This function can be named (arbitrarily) the Entrepreneurship Precision Function which, with respect to its structure, is capable to determine the amount of skewness of entrepreneurship status. In the breakdown of this function into different areas, negative, zero point and positive, the following additional information is remarkable:

1. Negative domain: in which the disequilibrium between total entrepreneurship and innovative entrepreneurship is considerable.

2. Positive domain: uncertainty and disequilibrium, as the measure of skewness, are striking therein also.

3. The zero point: in the case that this function is equal to zero, the precise amount of interaction between entrepreneurial activities (whether innovative, opportunity-based, mandatory and so on), as well as the interaction between exogenous and endogenous factors occurred within individuals will be balanced accurately. In such a case, the precision parameter is the measure that numerically discloses the amount of interaction among such activities.

Now, we call this function, arbitrarily, the Entrepreneurship Precision Function that its root will be an amount of precision parameter that shows the interaction of entrepreneurial activities affecting the economic development. We name the root of this function, arbitrarily, the Business Knowhow Rate. That is, in terms of entrepreneurship, the value of the precision parameter that causes $f(\alpha)$ to become zero is the approximate amount of knowledge, skill, know-how, educations, culture, and so forth of the people of the country in question. To get a further understanding of this function, see Figure 4. 


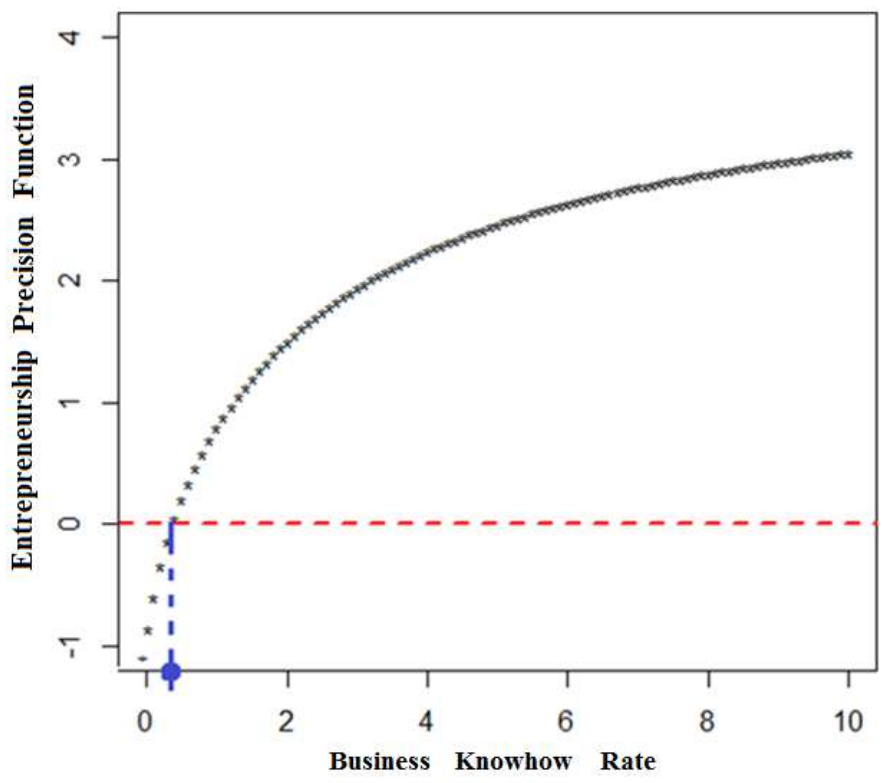

Figure 4: Entrepreneurship Precision Function Vs. Precision Parameter (Business Knowhow Rate) ; Source: Authors' own figure

In Figure 4, the blue dashed line makes a link between the curve of the Entrepreneurship Precision Function and the point of Business Knowhow Rate. Therefore, according to this figure, the mathematical definition of Business Knowhow Rate can be written as follows:

if $\exists A \in D_{A}$ and $B \in D_{B}$ so that $f(\alpha ; A, B)=0$ then $f^{-1}(0, A, B)=$ Business Knowhow Rate

Where $D_{A}$ and $D_{B}$ are the domain of $\mathrm{A}$ (as the Entrepreneurial Innovation Index) and B (as the Entrepreneurship Index), respectively.

Very powerful and scientific arguments there are behind the structure of the urn scheme models like the Blackwell-MacQueen urn scheme, Chinese Restaurant Process, Dirichlet Process. To this end, accurate implementation of some theoretical methods in some context, especially in the management science, will allow readers and researchers to move forward in identifying some intangible phenomena (e.g. entrepreneurship).

To sum it up all, this achieved model (equation (9)) although takes two predetermined values to be applied (i.e. Entrepreneurial Innovation Index and Entrepreneurship Index), but according to Figure 3 and Figure 4, and according to the limit of the function (8) it is observable that equation 
(9) will be able to describe the relationship between Entrepreneurial Innovation index, Entrepreneurship Index, and Economic Development which can be as the first formulization of the Schumpeter's claim over the innovative entrepreneurship as the economics' deriving force.

\section{Results}

\subsection{Overview}

Today, finding a mathematical formula explaining the relationship between various concepts is playing a significant role to study phenomena more accurately. More importantly, the importance of this problem will increase when most of the researchers acknowledge the importance of relationships among key factors while they find no source to be proved. For example, Schumpeter has declared that the innovation, especially in the field of entrepreneurship, influences the economic cycle, but except for some partial document, no mathematical and theoretical model suppers his claim

To this end, we tried to formularize the relationship between the total entrepreneurship and the entrepreneurial innovation by applying a stochastic process developed by statisticians.

The Blackwell-MacQueen Urn scheme and The Chinese Restaurant Process (CRP) were the stochastic models we exploited to reach the goals of the study.

In addition to making a formula to analyze the relationship between the total entrepreneurship and the entrepreneurial innovation, we were able to introduce a probability-based function to estimate the probability of choosing a business whether an innovative or repetitive business. As such, the nonparametric Bayesian approach was widely applied to justify the applicability of this predictor function that we named it, arbitrarily, "Decision Function".

\subsection{Discussion \& Conclusions}

Innovative entrepreneurship is considered an important pillar for economic development. According to Schumpeter "carrying out innovations is the only function which is fundamental in history". Hence, what we were looking for in this research was finding a mathematical and numerical relationship between economic development and entrepreneurship. Since many scholars 
have repeatedly argued that innovative entrepreneurship is an economic stimulus that can contribute to the development of a country and the health of the community, to this end, our endeavor was also in line with investigating a mathematical relationship between innovative entrepreneurship and total entrepreneurship.

As you studied, Figure 1 represented that innovation can strongly enhance the economic resilience of the country and also is able to prevent the recession in a society when facing external shocks and economic crises. The linear relationship (equation (1)) indicated that innovation can make the country more resistant to external crises and shocks. According to Figure (1), innovation is one of the most important factors (because the R-square in the estimated model is $85 \%$ ) which proves its impact on economic growth as well.

On the other hand, in order to model these two variables (Entrepreneurial Innovation Index and the Entrepreneurship Index), we used the Blackwell-MacQueen urn scheme and the Chinese Restaurant Process (CRP), which are a specific type of extended Dirichlet process, and also are widely used in the modeling of some non-statistical concepts. Since the Chinese Restaurant Process has a special skill in clustering the unclassified data, so the use of this process allowed us to apply the Entrepreneurial Innovation Index and Entrepreneurship Index simultaneously in the assessment of economic development.

Meanwhile, the existence of an unknown parameter in the Chinese Restaurant Process and the Blackwell-MacQueen process, which is referred to as the precision parameter $(\alpha)$, helped us to have further control over the Innovative Entrepreneurial Index. In other words, since innovationdriven entrepreneurship is the key factor in the growth of the economy and the development of society, so, a careful study on the Entrepreneurial Innovation Index will lead to a model generation. As a result, we illustrated, with the increase of the precision parameter, the amount of entrepreneurial innovation also grows. Therefore, we focused on the precision parameter in lieu of the Entrepreneurial Innovation Index.

With the use of the average function of clusters in the Chinese Restaurant Process, and assuming that the Entrepreneurship Index and Entrepreneurial Innovation Index are known, we were able to introduce a function called, arbitrarily, "Entrepreneurship Precision Function". Finally, we showed that the root of the Entrepreneurship Precision Function will provide a certain amount of precision parameter, which indicates the status of awareness, skills, know-how, capabilities, educations, culture and so on. This value was called, arbitrarily, the "Business Knowhow Rate". 
This index can be a basis for measuring the entrepreneurship development of countries, in which the ranking of countries also can be considered as one of its applicability. The high value of this index in a country indicates that more businesses are based on innovation, knowledge, skill, education, experience, etc. so the economy is more resistant and more flexible.

\section{Acknowledgment}

We are grateful to Dr. Nezameddin Faghih and the reviewers for their wonderful comments and suggestions throughout the review process. Additionally, we highly wish to thank our parents and family for inspiriting us during this research.

\section{Funding}

Not applicable 


\section{References}

Acha, V., and von Tunzelmann, G. N. (2004). Innovation in "low tech" industries. In J. Fagerberg, D. Mowery, \& R. Nelson (Eds.), Oxford handbook of innovation Oxford; New York.

Aldrich, DP., and Meyer, MA. (2014). Social capital and community resilience. Am Behav Sci. DOI: $10.1177 / 0002764214550299$.

Antoniak, C. (1974). Mixtures of Dirichlet processes with applications to Bayesian nonparametric problems. Ann. Statist., 2:1152-1174.

Bahadur, A., and Doczi, J. (2016). Unlocking resilience through autonomous innovation. Working Paper, Overseas Development Institute, London.

Baum R., J., Frese, M., Baron R. (2007). The Psychology of Entrepreneurship, Lawrence Erlbaum Associates, New York.

Bell, M., and Pavitt, K. (1993). Technological Accumulation and Industrial Growth: Contrasts between Developed and Developing Countries. Industrial Corporate Change, 2, 157-210.

Blackwell, D., and MacQueen, J. B. (1973). Ferguson distributions via Ploya Urn Schemes. The Annals of Statistics, 2, 353-355.

Bristow, G., Healy, A. (2018). Innovation and regional economic resilience: an exploratory analysis, The Annals of Regional Science, Volume 60, Issue 2, pp 265-284.

Capello R, Caraglui A, Fratesi U. (2015). Spatial heterogeneity in the costs of the economic crisis in Europe: are cities sources of regional resilience? J Econ Geogr. Doi: 10.1093/jeg/lbu053.

Coccia, M. (2010). Democratization is the driving force for technological and economic change. Technol Forecast Soc Chang 77(2):248-264. https://doi.org/10.1016/j. tech for.2009.06.007.

Coccia, M. (2014). Socio-cultural origins of the patterns of technological innovation: what are the likely interaction among religious culture, religious plurality, and innovation? Towards a theory of socio-cultural drivers of the patterns of technological innovation. Technol Soc 36(1):13-25. https://doi.org/10.1016/j. techsoc.2013.11.002.

Coccia, M. (2014b). Religious culture, democratization, and patterns of technological innovation, International Journal of sustainable society 6(4):397-418, https:// doi.org/10.1504/IJSSOC.2014.066771.

Coccia, M. (2017). A Theory of general causes of violent crime: Homicides, income inequality and deficiencies of the heat hypothesis and of the model of CLASH, Aggression and Violent Behavior, vol. 37, NovemberDecember, pp. 190-200, https://doi.org/10.1016/j. avb.2017.10.005.

Coccia, M. (2019). Theory of Development, A. Farazmand (ed.), Global Encyclopedia of Public Administration, Public Policy, and Governance, https://doi.org/10.1007/978-3-319-31816-5_939-1.

Cooke P., and Eriksson, A. (2011). White spaces innovation in Sweden: innovation policy for exploring the adjacent possible. VINNOVA, Sweden. 
Crudu, R. (2019). The Role of Innovative Entrepreneurship in the Economic Development of EU Member Countries, Journal of ENTREPRENEURSHIP, MANAGEMENT and INNOVATION DOI: https://doi.org/10.7341/20191512 JEL codes: O10, O11, O30, O52.

Davies, S. (2011). Regional resilience in the 2008-2010 downturn: comparative evidence from European countries. Camb J Reg Econ Soc 4(3):369-382.

Diodato, D., and Weterings, ABR. (2014). The resilience of regional labor markets to economic shocks: Exploring the role of interactions among firms and workers. J Econ Geogr 15(4):723-742.

Fagerberg, J. (2003). Schumpeter and the revival of evolutionary economics: an appraisal of the literature. Journal of Evolutionary Economics, 13, 125-159.

Edward J. Malecki. (2018). Entrepreneurs, Networks, and Economic Development: A Review of Recent Research, in Jerome A. Katz, Andrew C. Corbett (ed.) Reflections and Extensions on Key Papers of the First Twenty-Five Years of Advances (Advances in Entrepreneurship, Firm Emergence and Growth, Volume 20) Emerald Publishing Limited, pp.71 - 116.

Fagerberg, J., Mowery, D., and Nelson, R. (2004). The Oxford Handbook of Innovation. Oxford: Oxford University Press.

Faggian A, Gemmiti R, Jaquet T, and Santini I. (2018). Regional economic resilience: the experience of the Italian local labor systems. The Annals of Regional Science, Volume 60, Number 2, Page 393.

Faghih, N., Bonyadi, E., and Sarreshtehdari, L. (2019). Global Entrepreneurship Capacity and Entrepreneurial Attitude Indexing Based on the Global Entrepreneurship Monitor (GEM) Dataset, Globalization and Development, pp 13-55.

Ferguson, T. S. (1973). A Bayesian analysis of some nonparametric problems. The Ann. Statist, 1, 209-230.

Fuentelsaz, L., P Maicas, J., Montero, J. (2018). Entrepreneurs and innovation: The contingent role of institutional factors, Small Business Journal: Researching Entrepreneurship2018, Vol. 36(6) 686-711

Gerguri, SH., Ramadani, V. (2010). "The impact of innovation into the economic growth" Munich Personal RePEc Archive (MPRA), No. 22270.

Gerschenkron, A. (1962). Economic Backwardness in Historical Perspective, Cambridge (Mass.): The Belknap Press.

Granstrand, O. (2004). Innovation and intellectual property rights, in Fagerberg, J., Mowery, D., Nelson, R. (Eds.), The Oxford Handbook of Innovation. Oxford: Oxford University Press, 266-290.

Griffith, R., Huergo, E., Mairesse, J. and Peters, B. (2006) Innovation and productivity across four European countries. Oxford Review of Economic Policy, 22, 483-498.

Grossman, G. M., and Helpman, E. (1991). Innovation and Growth in the Global Economy. Cambridge (MA), MIT Press.

Hobday, M. (1995). East Asian latecomer firms, World Development, 23, 1171-1193.

Ignatove, A., (2019). Entrepreneurial Innovation key to a Sustanable and competitive European Union, Augustin ignatov,Academy of Economic Studies of Moldova, Volume 12 . 
Kline, S.J, and Rosenberg, N. (1986). “An Overview of Innovation”, in R. Landau and N. Rosenberg (eds) The Positive Sum Strategy: Harnessing Technology for Economic Growth, Washington D.C.: National Academy Press, pp. 275-304.

Lionnet, P. (2003), Innovation-The Process, ESA Training Workshop, Lisbon.

Lounsbury, M., Cornelissen, J., Granqvist, N. Grodal, S. (2019). Culture, innovation and entrepreneurship, innovation, VOL. 21, NO. 1, 1-12, Routledge Taylor \& Francis group https://doi.org/10.1080/14479338.2018.1537716.

Müller, P., and Quintana, F. A. (2004). Nonparametric Bayesian data anal-ysis. Statist. Sci, 1, 95-110.

Nafziger, EW. (2005). Theories of economic development. In: Economic development. pp 123-164. https://doi. org/10.1017/CBO9780511805615.006.

Ray, G. F. (1980). Innovation as the Source of Long Term Economic Growth, Long Range Planning Vol. 13

Schumpeter, J. A. (1934). The Theory of Economic Development: An Inquiry into Profits, Capital, Credit, Interest, and the Business Cycle. Cambridge, MA: Harvard University Press.

Śledzik, K. (2013). Schumpeter's View on Innovation and Entrepreneurship, SSRN Electronic Journal, DOI: $10.2139 /$ ssrn.2257783.

Stephanie, D., S., Raetze, S., Scheuch, I. (2019). The role of diversity in organizational resilience: a theoretical framework, Business Research, pp 1-37.

Todaro, MP., and Smith, SC. (2003). Economic development, Parson Addison Wesley, Harlow.

Tomma, S., Grigorea a, A., Marinescu, P. (2014). "Economic development and entrepreneurship" Procedia Economics and Finance 8, $436-443$.

World bank report, BRIEF, Innovation \& Entrepreneurship, July 8, 2015.

Yeager, Tim. (2018). "Institutions, Transition Economies, and Economic Development”. 1st Edition 1999, Politics \& International Relations, eBook ISBN: 9780429499760, pp 184, DOI: https://doi.org/10.4324/9780429499760. 
Figures

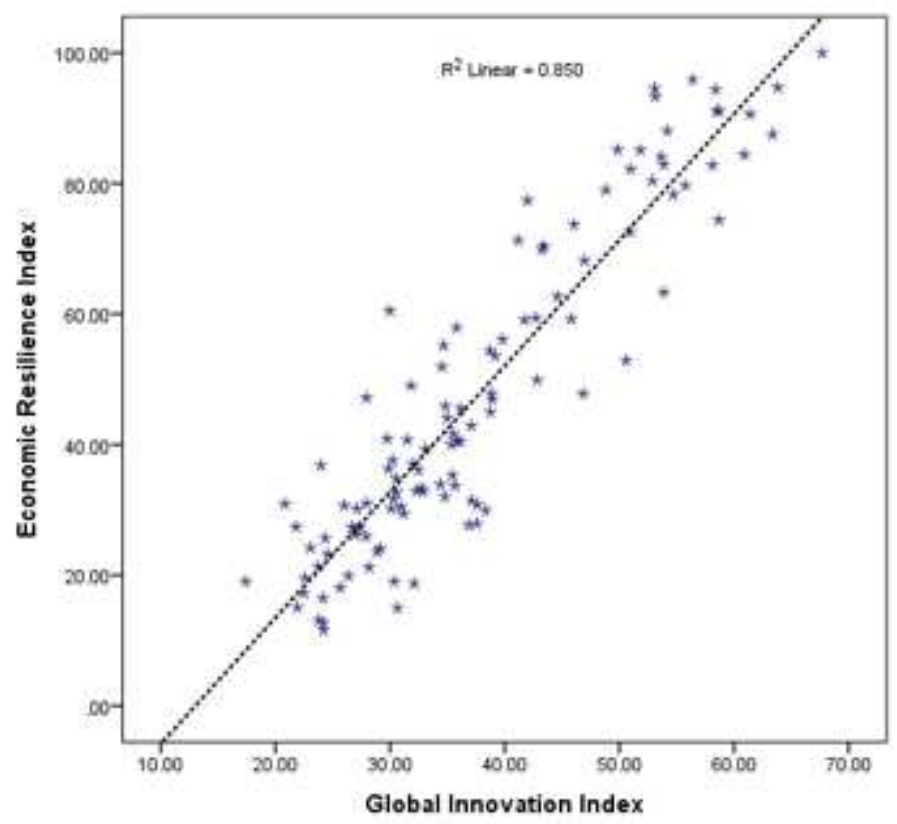

\section{Figure 1}

Relationship between Economic Resilience Index and the Global Innovation Index; Source: Authors' own figure
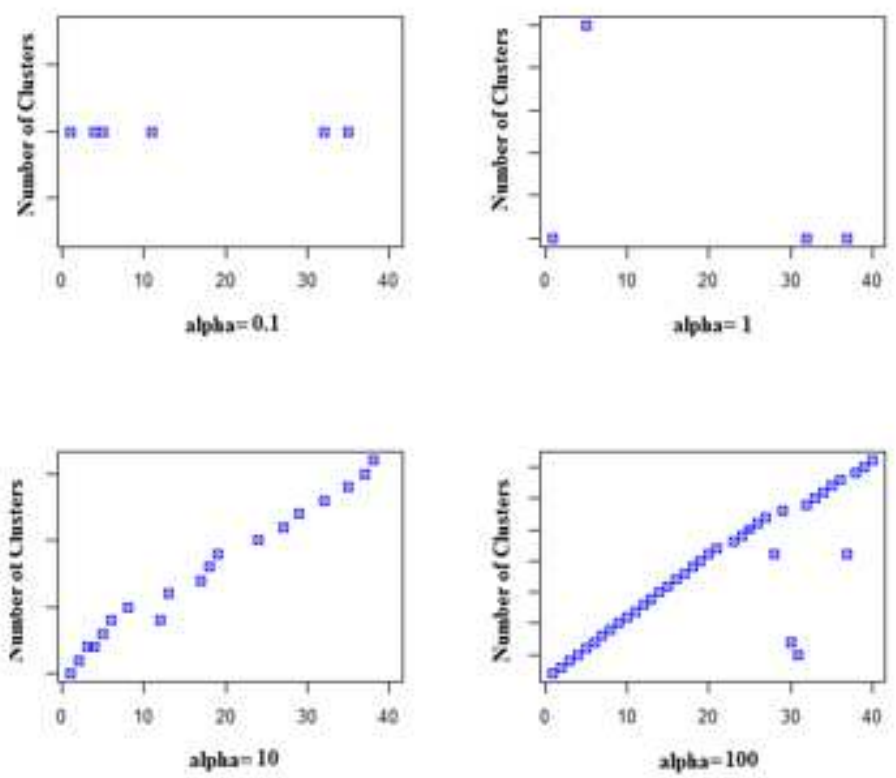

Figure 2

The growth of the number of clusters (innovative businesses herein) when the precision parameter increases; Source: Authors' own figure 


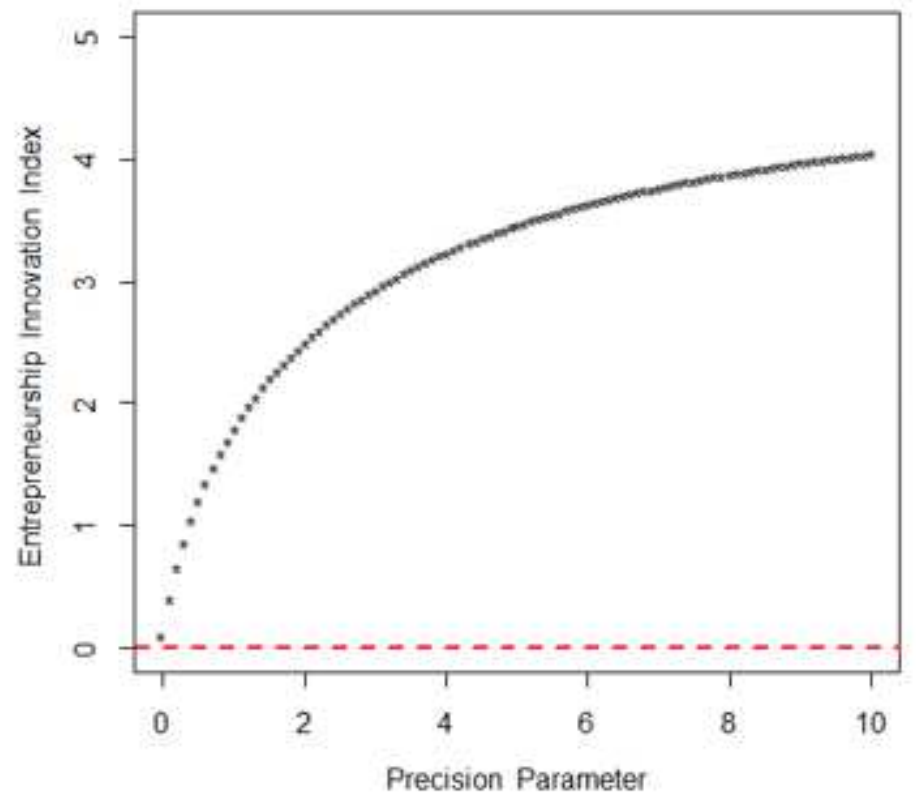

Figure 3

The relationship between the precision parameter and the Entrepreneurial Innovation Index; Source: Authors' own figure

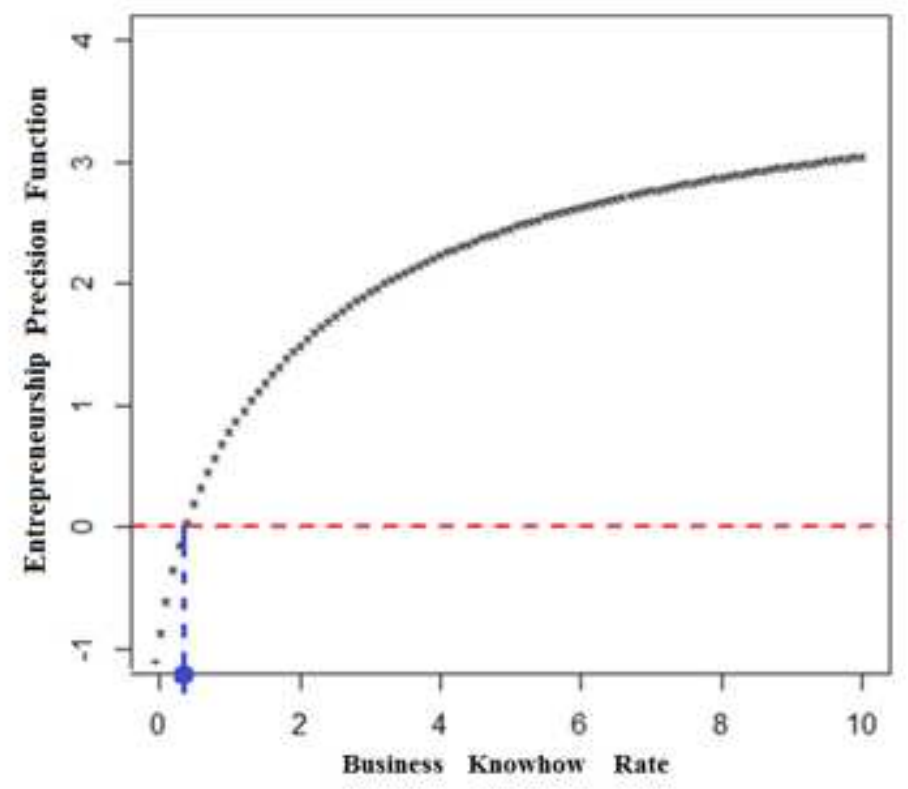

Figure 4

Entrepreneurship Precision Function Vs. Precision Parameter (Business Knowhow Rate) ; Source: Authors' own figure 